\title{
A model-based Decision Support System for multiple container terminals hub management
}

\author{
Francesco Facchini ${ }^{a *}$, Francesco Boenzi ${ }^{\mathrm{a}}$, Salvatore Digiesi ${ }^{a}$, Giovanni Mummolo ${ }^{\mathrm{a}}$ \\ aDipartimento di Meccanica, Matematica e Management, Politecnico di Bari, Bari, Italy \\ *francesco.facchini@poliba.it
}

\begin{abstract}
Paper aims: To develop a model-based Decision Support System (DSS) that allows identifying the best strategy of the inter-/intra-terminal flows of the containers in order to increasing the performance of the hub under economic and environmental perspective.
\end{abstract}

Originality: The adoption of a dry port can effectively solve the congestion problem of a terminal only if an integrated sustainable solution (dry port location and container strategy storage) is identified.

Research method: The model is based on a heuristic computational algorithm for non-linear programming.

Main findings: The application of DSS to a full-scale numerical case show the model capabilities in identifying the optimal logistic strategies ensuring a low CF and in optimizing the cost due to transport activities.

Implications for theory and practice: It is possible to identify different strategies allowing to obtain an eco-friendly solution reducing, at same time, the costs for a given number of containers to be handled.

\section{Keywords}

Sustainable logistics. Container terminal. Dry port. Carbon footprint. Material handling.

How to cite this article: Facchini, F., Boenzi, F., Digiesi, S., \& Mummolo, G. (2018). A model-based Decision Support System for multiple container terminals hub management. Production, 28, e20170074. https://doi.org/10.1590/01036513.20170074.

Received: Oct. 3, 2017; Accepted: July 12, 2018.

\section{Introduction}

In the last years the adoption of containers in maritime transport is constantly growing. According to the International Development Association (IDA) of World Bank Statistic, between 2000 and 2014, the worldwide container traffic has grown from 225 million of Twenty-foot Equivalent Units (TEU) to 680 million TEU, with an increase of about 200\%. The forecasts suggest a continuous increasing trend of the container traffic, and in 2020 a worldwide traffic of 1 billion TEU is expected (Drewry Maritime Advisors, 2015). European maritime regions are highly active in terms of trade and shipping activities: based on the gross weight of goods transported, the 29.7\% of Short Sea Shipping occurred in the Mediterranean (Amerini, 2010). The main reasons of the maritime freight transport growth rely on EU liberalisation of the internal market combined with a declining of the real price of maritime transport (from 1998 to 2013 fuel prices increased of 790\%, mainly affecting air and road transport modalities costs) and with the introduction of new environmental regulation oriented to incentivize further emission reductions and energy efficiency in freight transport. Moreover, strong pressure exerted by mass media and EU legislation imposed multiple new challenges to business organizations in terms of environmental impact and reduction in carbon foot- print (Boenzi et al., 2015; Digiesi et al., 2016; Facchini et al., 2016).

In this scenario and with the actual growing trend, the seaport congestion in Europe is expected to dramatically rise; a strong indication of high congestion of the container terminals is given by estimates of capacity utilisation of most seaports. The operation conditions of most terminal hub are very close to their capacity limits, this is 
especially the case of the seaports located in North-European area. In many cases the better solution could be the expansion of the seaports capacity in order to increase the operational efficiency of the maritime terminals, but in most European seaports this is not possible due to economical and urban planning constraints. Therefore inefficiency and congestion are the biggest problems faced nowadays by a terminal hub. Moreover, in last years the logistics activities have reached a high degree of complexity, thus requiring a considerable efforts both under the technical (Material Handling Equipment - MHE) and the organisational (Material Handling Strategy - MHS) perspective in order to ensure a high level of productivity and to satisfy the container shipping customers. Recently many scientific studies were devoted to solve the gate congestion problem in container terminals focusing on the allocation and scheduling issues.

In Figure 1, a conceptual scheme of a container terminal is depicted. As shown, it is possible to distinguish five main areas, in which different operations are performed, namely berth(s), quay, transport, (storage) yard, and terminal gates.

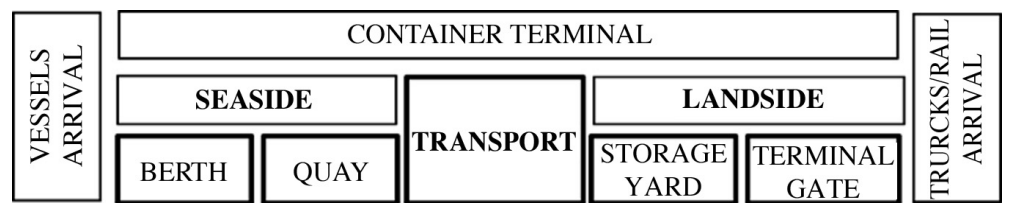

Figure 1. Container terminal conceptual scheme.

Traditionally, in scientific studies the main focus was to provide models allowing to optimize the layout and/or operations management in each area of the container terminal, in order to jointly increase efficiency and reduce costs. Model proposed in the past often were focused only on one single area of container terminals, neglecting the strong correlation between activities performed in all areas. Studies focusing on the container terminals "seaside" (berths and quay) traditionally focused on Berth Layout (BL), Berth Assignment Problem (BAP), Quay Crane Assignment Problem (QCAP), and Quay Crane Scheduling Problem (QCSP). A review of contributions appeared in scientific literature between 2004 and 2012 is in Carlo et al. (2015). MHE selection and sizing as well as routing and dispatching strategies to be adopted are the most common problems investigated in scientific literature dealing with transport area of a container terminal. A review on papers appeared in scientific literature on these topics is in Carlo et al. (2014a). Finally, research on container terminal "landside" (storage yard and terminal gates) usually are focused on the layout of storage yard, on optimal allocation of container, on MHE selection and scheduling, as well as on trucks arrival management systems. A review on scientific studies on these topics is in Carlo et al. (2014b). In the reviews above mentioned, Authors noticed that in the past few studies were devoted to solve an integrated problems, that is a problem considering at once two or more areas of a container terminal. On the contrary, in recent scientific literatures it is quite common to find contributions dealing with an integrated problem. Due to the complexity of the models proposed to jointly identify optimal allocation and scheduling in two or more areas of a container terminals, Authors adopt simulation or define ad hoc search algorithms to reduce the computational time required to find solutions of the proposed models.

In Venturini et al. (2017) a multi BAP with optimization of vessels speed is formulated and solved under the hypothesis of a collaborative approach among ports in order to minimize energy consumption and total operational time. In Agra \& Oliveira (2018), authors define a Mixed Integer Programming (MIP) model to solve the integrated BAP/QCAP/QCSP problem, and adopt a rolling horizon heuristic approach to find solutions allowing to minimize total vessels service completion time.

In most investigations in the landside of container terminals it is assumed that the container positions are fully or partly predetermined, in these cases different strategies can be adopted for optimize the containers handling in a simulation environment, in order to identify where to place a new or reshuffled container (Dekker et al., 2006). Zhang et al. (2003) address the storage space allocation problem in the yard using a rolling-horizon approach. The problem is split into two main levels: the first consisting of placing the total number of containers in each block at scheduled time period, the second level is focused on identifying the number of containers associated with each vessel in order to minimize the total distance due to transport of containers between yard blocks and the ship berthing location. The authors deal with four types of containers: inbound containers on vessels, inbound containers to be stored in yard blocks, outbound containers, and outbound containers already stored in yard blocks. A genetic algorithm (GA) is developed in Bazzazi et al. (2009) to solve the problem related to the temporary allocation of inbound/outbound containers in a terminal. In their study the authors implemented the $\mathrm{GA}$ in order to minimize the storage/retrieval movements required for the allocation of the containers 
and to identify the best strategy for reducing the operations for the relocation of containers in the Stacking Area (SA). In many other investigations, integrated solution addresses the assignment of storage locations to containers, which includes the allocation of space for containers moving into and out of the storage yard as well as re-handling. Typically, decision support systems recently developed are designed for particular terminal layouts, they are based on simulation techniques that assume the truck arrival times or distributions known a priori or adopt decision trees as an attempt to support real world decisions (Kim et al., 2000). An interesting model was developed by Cheung et al. (2002) for identifying, given the forecasted workload distribution in yard blocks for different time periods, an optimal solution allowing to minimize the MHE workload by changing the schedule and routes parameters in the yard. In this case, the authors adopted a multiple rubber-tired gantry cranes (RTGs) as equipment, the problem is formulated adopting a Mixed Integer Program approach and solved by different approximation of the Lagrangian relaxation method. In Froyland et al. (2007), authors present a three-stage algorithm, adopting as MHE a multiple semi-automated rail mounted gantry cranes (RMG), finalized to manage: the scheduling of cranes, the short-term control of the container stacking, and the allocation of delivery locations for trucks and other container handling equipment. The assessment that it carried out shows that the heuristic approach, developed by means an computational evaluation, allows to identify an effective solution 8\% above a lower bound of optimal RMG utilization. More recently, Lin \& Chiang (2017) defined a heuristic based on decision rules in order to find solution of the Storage Space Allocation Problem (SSAP) in the yard area of container terminals. The same problem is faced in the work of Le \& Knust (2017), in which Authors propose three different models (MIP models) considering stacking constraints and containers arrival data uncertainty. A simulation model is developed in Legato \& Mazza (2017) in order to identify the optimal storage yard configuration in case of the adoption of straddle carriers for the containers handling in the yard area. The minimization of container reshuffling is considered in the work of Ku \& Arthanari (2016), in which the Authors developed a stochastic dynamic programming model with the aim to evaluate the optimal relocation of containers in the storage yard. In Kiani et al. (2010), Authors adopt a Taylor Il simulation software in order to develop a queuing based simulation methodology that may assist the terminal operators in minimizing truck congestions. In order to reduce congestions in terminal gates, Phan \& Kim (2015) developed a decision making model supporting the negotiation process between trucks companies and terminal operators with the aim of smoothing trucks arrival in peak hours. The adoption of ICT technologies has been also investigated in scientific literature with the aim of reducing operational time at terminal gates and hence congestion. In order to improve efficiency in container terminal, ICT and RFID technologies are adopted. Especially in terminal gates, these technologies allow speeding-up clearance processes, thus reducing congestion (Kadir, 2017).

Despite many efforts in new forms of technology, work organization or by information systems, in most cases the problem of container congestion in terminal hub has not been solved. The lack of a proper manoeuving area, a container stacking area, and an operational area, significantly reduce the average terminal productivity (evaluated as the number of container handling per one working hour) and increase the dwell time of vessel in seaport. In these cases, the only solution is the increase of the seaport capacity by physically expanding existing ones, or by (re)building logistic infrastructures, but this is at considerable cost and effort, that require reliable investments evaluation (Ambrosino \& Sciomachen, 2017). In order to solve the containers handling performance due to a limited terminal area in 2009, Roso introduced a new concept of dry port, as a tool for solving the containers congestion problem, rather than a simple area, directly connected to seaport(s), where customers could leave or pick up the containers.

Basic functions of the dry port should be able to provide handling services, custom control and a temporary area for loading and unloading of containers. In many cases, facilities of the dry port can be extend providing further value-added services as full export/import processes and the consolidation activities. In order to identify and evaluate the external factors affecting the performance of the seaport and the implementation of the dry port, in scientific literature many studies are focused on Politics, Economic, Social, Technology, Environment and Legal aspects, according a PESTEL analysis approach. As far as concern politics aspects, it is clear that a good relationship and a close cooperation between government and private sector play an important role for the development and the implementation of the dry port. In Europe the Public Private Partnership (PPP) strategy allows to share obligations, risks, and investments. Consistently with this purpose, the building and the operation of most European dry port is based on the involvement of many public and private stakeholder (providers, shipping, terminal operators, logistic forwarders, etc.). Under economic perspective, there are many valued-added services provided by the dry port (container freight station, container maintenance, consolidation and distribution centre, etc.) but above all the implementation of the dry port allows to reduce the traffic congestion caused by the increase of flow of containers, improve the storage capacity of the seaport and introduce greater flexibility for the freight transhipment between maritime and ground transport. Both aspects may contribute to cost reduction, improving at the same time the reliability of the service and offering further 
value-added services for the users. The social factors are mainly related to the management. Although it does not have a direct relationship with the operational process, an efficient strategy oriented to the adoption of an aggressive marketing approach would allow attracting new business in the hinterland (Padilha \& $\mathrm{Ng}, 2012$ ). Consistently with the improvement of the efficiency of the dry port, new technology devices are required in order to optimize the operational performance and support the maintain safety procedures. At this scope an electronic gateway linking the trade users from dry port to terminal operators allows to share the information that encourage the interaction and the level of collaboration and coordination between different stakeholders (Harris et al., 2015). Therefore the ICT systems improve the service in terms of productivity, efficiency, accuracy, monitoring and control of processes information. Considering the environmental factors, in many cases the lack of dry port requires work to enlarge of the existing maritime terminal. In recent scientific literature, the dry port has gained much attention as an effective solution to container terminal congestion. A review of scientific contributions appeared in scientific literature between 2007 and 2013 is in (Saglam et al., 2105). The dry port location problem has been largely investigated in last years. In Ambrosino \& Sciomachen (2014), a MIP model is defined in order to solve identify the optimal location of dry port in a multimodal logistic networks. In Nguyen \& Notteboom (2016), Authors defined a conceptual framework in order to jointly consider multiple criteria in the evaluation of dry port location.

Considering the environmental factors, the implementation of dry port avoids the enlargement of existing maritime terminal. The environmental impact caused by these kind of works could be very high; indeed changes due to possible interference of the hydrological process to water system could potentially damage the marine ecosystem, on the contrary the dry port implements a most eco-friendly infrastructure. As far as concern the emission due to containers handling in a congested seaport, previous research conducted by liao et al. (2009), show that in Taiwan the dry port adoption was able to reduce of $60 \%$ the emission of the seaport activities. Moreover, a similar research conducted in London estimated that the emission due to Freight Construction Consolidation was reduced to $25.7 \%$ (Zanni \& Bristow, 2010). Under legal perspective the implementation of the dry port can significantly increase the security service, as an example the case of the Coslada Dry Port in Madrid, where an inspection of the containers is regulatory provided.

According to the aspects above mentioned, the dry port represents a good choice allowing to improve the handling of containers in seaports and leading to identify more efficient logistics solutions for shippers in the seaport's hinterland.

Consistently with this purpose, in Roso et al. (2009) authors defined three dry port categories: close, mid-range and distant, and for each of them define the benefits under the perspectives of the actors involved. In order to contribute to the concept of logistics sustainable management, whit the purpose of reducing logistic costs and minimizing the environmental impact, Digiesi et al. suggested a model allowing to identify the optimal means of transport and the optimal stock level both in case of deterministic product demand and lead time (Digiesi et al., 2012), as well as in case of lead time variability (Digiesi et al., 2013) and variable product demand (Digiesi et al., 2015).

It is clear that the implementation of the dry port in a container terminal radically changes the traditional handling process of the terminal. In most cases the role of the dry port is an effective interface for all the hinterland shippers; it allows to transfer the container storage and sorting functions from congested transhipments point to inland locations, where more space is available. The connection between seaport and dry port are ensured by fast and reliable service (by road or by rail) that allows to consider the inland sites as a real extension of the seaport lies in a substantial decrease of the seaport zone congestion (Crainic et al., 2015). If on one hand the identification of a dry port leads to many benefits on terminal congestion under economic and environmental perspective, on the other hand the transport of the containers from the seaport to the dry port, requires resources, generates extra costs, and introduce a further polluting source due to emissions generated by transport means adopted for the containers handling outside the seaport.

Therefore, there are issues that require strategical evaluations (e.g. container distribution network, dry port localization, etc.), tactical assessments (e.g. scheduling of the train or road containers transfer service, sizing of the shuttle fleet, etc.) and operational approaches (e.g. container logistic in seaport and in dry port, identification of seaport material handling equipment, etc.). For each case, proper variables and criteria have to be selected, and the best strategy under economic and environmental perspectives has to be identified.

Despite the increasing interest in dry-port systems, the literature on freight logistics management shows a lack of contributions addressing the optimization problems related to freight distribution processes, at a strategically, tactical and operational level. Nowadays most decisions regarding the utilization of dry port area, the kind of dry port to be implemented, the handling of containers from seaport to dry port, and many other relevant aspects related to the management of dry port and its localization are mainly based on the expert experience. 
There is a lack in scientific literature on methods and techniques allowing to evaluate the overall economic and environmental aspects related to the implementation of a dry port and to the adoption of different container handling strategy (inside and outside of the seaport). In previous contributions appeared in scientific literature, the dry port location problem is faced independently from the strategy to be adopted in the storage yard of the container terminal. In Authors' perspective, the adoption of a dry port can effectively solve the congestion problem of a terminal only if an integrated sustainable solution is identified and adopted. Starting from the terminal capacity requirement, the solution has to include the optimal distance of the dry port, the handling strategy to be adopted (how many containers to be stored in the sea port yard and in the dry port), the optimal stack configuration (in both sea port and dry port), and the MHE to be adopted, since this decision variables are not independent, and have to be evaluated as the solution of an integrated problem. Moreover, feasible solutions have to be evaluated on both a cost and an environmental perspective, in order to support decision makers in achieving priority goals. In Authors knowledge, in existing scientific literature there are no models available to solve this integrated problem. The challenge of this study consists of defining a model-based Decision Support System (DSS) allowing to optimize the inter-terminal and intra-terminal flows, jointly minimizing the cost and the environmental impact (evaluated as Carbon Footprint Index) due to the overall handling of containers (inside and outside the seaport). Consistently with the purpose of the paper, the proposed DSS provides, on the basis of distance from seaport to dry port and considering the MHE adopted, a proper container handling strategy (containers to be stocked in seaport and in dry port as well as the stacks configurations) in order to minimizing the overall costs and the carbon footprint of the handling activities.

The effectiveness of the proposed DSS has tested on numerical experiments based on a full case study. Results obtained allow to identify a container handling strategy able to ensure significantly cost and emission savings. The proposed DSS can be adopted for identifying and estimating, for each case, the potential benefits achieving through the implementation of a dry port. Moreover, the DSS can support the decision makers in identifying, case-by-case, the optimal strategy to be adopted in order to ensure a sustainable and cost-effective container handling management.

The rest of the paper is structured as follows: in Section 2 the process of loading/unloading is introduced; in Section 3 the proposed model is described; results obtained in case of a full scale numerical experiment are in Section 4; finally, conclusion of this work are in Section 5.

\section{Problem description}

The unloading process of containers can be divided into different sub processes: in a first phase, the inbound containers have to be taken off the ship by means of a Quay Cranes (QCs). Once the spreader of QCs locks the container, it is lifted, moved over the dock, and placed on a truck chassis (trailer) that allows transporting it to the quayside. In a second phase (Figure 2) the containers (empty or full) are transferred from quayside to a dedicated Stacking Area (SA) by means of one or more Material Handling Equipment (e.g. sidelifts, reach stackers, etc.) In a third phase the containers are stored in SA according to different storing modality (stored on a chassis or stacked on the ground) and different layouts: area, block and linear stack are the most common layouts (Brinkmann, 2011). In most cases the same Material Handling Equipment (MHE) used for the transport of containers from the quayside is adopted for the storing activities; alternatively, a dedicated MHE (e.g. yard

a.

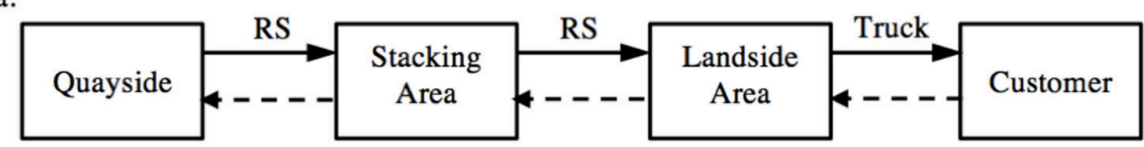

b.

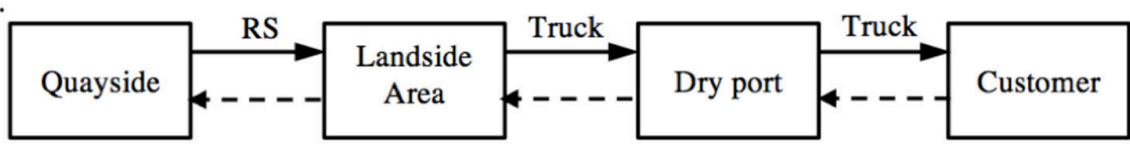

inboud containers flow (I)

outboud containers flow (II)

Figure 2. Container handling cycle by means Reach Stackers (RS) and Truck in case of SA inside the seaport (a) and in case of dry port area outside of the seaport (b). 
cranes) can be adopted. Finally, the containers are loaded on trucks in a landside area, by means of the same MHE adopted in the earlier phase, and they are transported outside of the seaport. The loading process (outbound containers) requires the same activities, starting from the last phase until the first phase.

The identification of a dry port could change the process above described, therefore the outbound and inbound containers could be transported directly from seaport to the dry port and vice versa. In both cases it is not required the storing of the containers in the SA.

\section{The DSS model}

The DSS developed is based on a heuristic computational algorithm for non-linear programming that allows identifying the number of containers to be stored in the seaport $\left(N_{I}\right)$ and in the dry port $\left(N_{2}\right)$ for different distance values $(D)$ between them allowing to minimize the overall cost (Equation 1) and the Carbon Footprint (Equation 5) due to inter- /intra-terminal flows of containers. For this purpose the input parameters required by the model are: the overall number $(M)$ and size $\left(d_{x}, d_{y}, d_{z}\right)$ of containers to be handled; technical specifications of the road/non-road vehicles, the hourly average costs per square meter (excluded management cost) for the rental of the areas in- side the seaport and of dry port areas $\left(C_{P O R T}, C_{D P}\right)$ and the hourly average cost (staff cost, taxation, amortization, etc.) due to $\mathrm{MHE}$ and trucks $\left(C_{M H E}, C_{T R K}\right)$.

\subsection{Assumption}

The DSS is developed under the following assumption:

1. The MHE considered in the model are: mobile harbor crane for the operations of ship-to-shore; reach stackers (RS) for the transport (inside the seas area), the store/retrieval of the containers from the SA and for the operations of load/unload; trucks for the transport of containers to the dry port area;

2. The containers, stackable and characterized by the same sizes, are stocked in the SA according to a stacking on the ground strategy adopting a "block" lay-out; they are stored in stockpiles of the same height (see Figure 3), and each stockpile can be accessed only from the front-side $\left(F_{S}\right)$;

3. The time required for re-handling of the containers is not considered;

4. The speed of the RS does not depends on the weight of the container carried; for safety reasons an average speed value (for horizontal and lifting movements) equal to 50\% of the maximum speed of the RS is assumed;

5. A 'transit point' strategy is considered for the dry port, therefore most containers are 'directly' picked up from customers;

6. In initial conditions, there are not containers stored in the SA or in the dry port;

7. The time required for transporting containers from the SA to the landside area is negligible (in many seaports the landside area and SA are integrated);

8. The transport of containers to customers is not considered in the model;

9. The rental cost of the dry port decreases with its distance from the seaport.

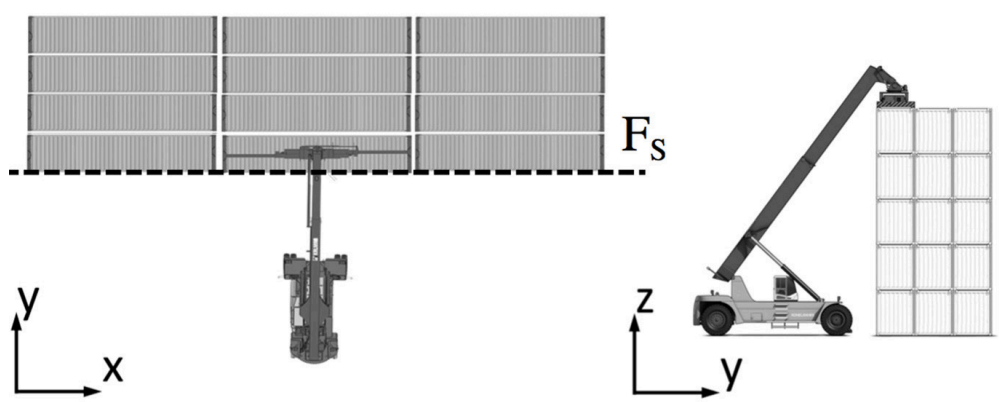

Figure 3. Layout of stackable containers, according to $x y$-axes and $y z$-axes, considering the picking by front-side (Fs). 


\subsection{Cost function}

The cost function $(\mathrm{C} f)$ to be minimized is:

$$
C f=C_{M H E} \cdot\left(2 \cdot T_{S A}+N_{1} \cdot T_{f}\right)+k_{1}+\mu \cdot k_{2}+N_{2} \cdot T_{t} \cdot C_{T R K}
$$

where $T_{f}$ is the average time required for all the operations finalized to docking/undocking of one container from the spreader; the parameter $\mu$ identifies the 'containers in dry port rate': this value is evaluated as the ratio of the number of containers to be stored in the dry port on the overall number of containers' transported; this means than the remaining part of the containers transported to the dry port (1- $\mu)$, will not be stocked in the dry port but they will be directly picked up from customers (according to assumption number 5 in previous section). In the numerical simulation presented in section 4 , a $\mu$ value of $20 \%$ is assumed.

As far as concern $n_{x}, n_{y}$ and $n_{z}$ parameters, they represent the number of containers stored in SA according to the $\mathrm{x}, \mathrm{y}$ and $\mathrm{z}$-axis respectively; $k_{1}$ and $k_{2}$ are the rental costs of the areas inside the seaport and in the dry port and are obtained by means of the following equations:

$$
\begin{gathered}
k_{1}=T_{w} \cdot C_{P O R T} \cdot d_{x} \cdot d_{y} \cdot n_{x} \cdot n_{y} \\
k_{2}=T_{w} \cdot C_{D P} \cdot d_{x} \cdot d_{y} \cdot N_{2}
\end{gathered}
$$

$T_{w}$ is the average waiting time of the overall containers stocked (in seaport or dry port), $T_{t}$ is the time required for the transport of $N_{2}$ containers from the seaport to the dry port and $T_{S A}$ is the time required for the handling of the containers (lifting up and horizontal movements by the RS) during the storage and their retrieval from the SA; $T_{S A}$ can be expressed as:

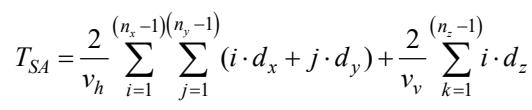

In Equation 1, the value of $T_{S A}$ is doubled since the DSS considers the time required for the storing and picking phases of the single container from/to the stockpile.

$v_{h}, v_{v}$ (Equation 4) represents the average travel speed (h as subscript) and lifting speed ( $v$ as subscript) of the MHE adopted in the seaport. The computational algorithm adopted allows identifying $n_{x}, n_{y}$, and $n_{z}$ in order to optimize the time required by MHE for storing $N_{l}$ containers in the seaport.

\subsection{Carbon footprint evaluation}

In order to evaluate the environmental impact related to the handling of the containers in the seaport and in the dry port, the CF due to different activities is evaluated. The function to be minimized for this purpose is showed in Equation 5.

$$
C F f=C F_{M H E} \cdot\left(2 \cdot T_{S A}+N_{1} \cdot T_{f}\right)+C F_{T R K} \cdot N_{2} \cdot T_{t}
$$

where $C F$ is the average equivalent carbon dioxide per hour emitted by 'road' (TRK as subscript) and 'non-road' (MHE as subscript) vehicles adopted; it is a function of the average fuel consumption ( $\rho_{M H E}$ and $\rho_{\text {TRK }}$ ) and of the average travel speed of the truck transporting the containers from port to dry port (Equations 6 and 7):

$$
\begin{gathered}
C F_{T R K}=0.1 \cdot \rho_{T R K} \cdot v_{T R K} \cdot E R \\
C F_{M H E}=\rho_{M H E} \cdot E R
\end{gathered}
$$

As far as concern the Emission Rate (ER) parameter, its value identifies the amount of the tailpipe emissions of $\mathrm{CO}_{2}$ from the burning of a litre of fossil fuel (diesel, petrol or LPG). In most cases the simplest way to calculate tailpipe emissions of carbon dioxide is to measure the average hourly fuel consumption of the equipment adopted in the container handling cycle. 


\subsection{Mathematical model description}

The output of the model is achieved by means of the identification of the $N_{1}, N_{2}$, and D values according to the value of the following input variables:

- Containers data (overall number of containers to be handled and containers' size);

- MHE features (technical specification of the MHE adopted i.e. speed, consumption, etc.);

- Area and MHE running cost (seaport/dry port's area rental cost, and equipment operative cost);

- Downtime (average time during which the container is not handled).

The sum of the numbers of containers to be stocked in seaport and in the dry port ( $N_{1}$ and $N_{2}$, respectively) will be equal to the overall number of the containers to be stocked $(M)$.

The mathematical model is based on a heuristic computational algorithm implemented by following instructions:

1. Input data-set;

2. Identify G matrix constituted by $G_{i}$-array each of them characterized by possible permutations of integer number $N_{1}$ and $N_{2}$ on the basis of the overall number of containers to be handled $(M)$ :

$$
G=\left[\begin{array}{cc}
N_{1} & N_{2} \\
N_{1}^{\prime} & N_{2}^{\prime} \\
\cdots & \cdots \\
N_{1}^{\prime \prime} & N_{2}^{\prime \prime}
\end{array}\right] \text { with } N_{1} \neq N_{1}^{\prime} \ldots \neq N_{1}^{\prime \prime} \text { and } N_{2} \neq N_{2}^{\prime} \ldots \neq N_{2}^{\prime \prime}
$$

where the sum of the parameters in each row (G-array) are equal to $N$.

3. Identify a $R$ matrix constituted by $R_{j}$-array each of them characterized by possible permutations of integer number $n_{x}, n_{y}$ and $n_{z}$ on the basis of the overall number of containers to be stocked in seaport $\left(N_{l}\right)$;

$$
R=\left[\begin{array}{ccc}
n_{x} & n_{y} & n_{z} \\
n_{x}^{\prime} & n_{y}^{\prime} & n_{z}^{\prime} \\
\cdots & \ldots & \ldots \\
n_{x}^{\prime \prime} & n_{y}^{\prime \prime} & n_{z}^{\prime \prime}
\end{array}\right] \text { with } n_{x} \neq n_{x}^{\prime} \ldots \neq n_{x}^{\prime \prime} \text { and } n_{y} \neq n_{y}^{\prime} \ldots \neq n_{y}^{\prime \prime} \text { and } n_{z} \neq n_{z}^{\prime} \ldots \neq n_{z}^{\prime \prime}
$$

where the product of the parameters in each row $\left(R_{j}\right.$-array) are equal to $N_{l}$.

4. Evaluate for each $G_{i}$ and the corresponding $R_{j}$ identified, $C f$ (Equation 1) and $C F f$ (Equation 5);

5. ldentify and show the minimal value of cost, carbon footprint, and corresponding parameters (output of the model) values.

\section{Numerical simulation}

In order to evaluate the DSS effectiveness, the model has been applied to a full-scale numerical case. The data adopted for cost and environmental evaluation are listed in Table 1.

According to the cost evaluation obtained by DSS (see Figure 4), there are three mainly strategies for three different range of distance:

- For $D<14 \mathrm{~km}$, the most cost-effective strategy requires that all containers ( $N=800$ units) are stored in the dry port, in Figure 4a this strategy is shown as line $(0 ; 1)$ where 0 identify the percentage of the total number of containers $(M)$ to be stocked in seaport while 1 identifies the percentage of $N$ containers to be stocked in dry port, therefore according this strategy $N_{1}=0$ and $N_{2}=800$; 
- For $14 \mathrm{~km} \leq D<21 \mathrm{~km}$, the most cost-effective strategy requires that a percentage of $75 \%$ of overall container are stored in the seaport, and the rest is stored in the dry port (shown in Figure 4a as line with '0.75;0.25' label), therefore, $N_{1}=600$ and $N_{2}=200$;

- For $\mathrm{D} \geq 21 \mathrm{~km}$, the most cost-effective strategy requires that all containers are stored in the seaport, the cost of this strategy not depends by distance from seaport to dry port. Therefore in this case, the trend of the handling cost is shown as a line parallel to the $x$-axes (Figure 4a).

As far as concern the $\mathrm{CF}$, the model identifies different optimal strategies in different distance ranges:

- For $D<10 \mathrm{~km}$ the strategy characterized by the lowest CF requires that the same number of containers is stored in the seaport and in the dry port, therefore: $N_{1}=400$ and $N_{2}=400$, in Figure 4b this strategy is shown as line $(0.5 ; 0.5)$ where the percentage of $N$ containers to be stocked in seaport and in dry port is the same;

- For $10 \mathrm{~km} \leq D<17 \mathrm{~km}$ the strategy characterized by the lowest CF requires that a percentage of 75\% of all the containers is stored inside the seaport, and the rest in the dry port, in the examined case $N_{1}=600$ and $N_{2}=200$;

- For $D \geq 17 \mathrm{~km}$, the most eco-friendly strategy requires that all containers are stored in the seaport.

On the basis of both evaluations, the model suggests the adoption of dry port located at distance $(D)$ of less then $17 \mathrm{~km}$. In this case there are different handling cost-effective strategies allow ensuring a lower environmental impact if compared to scenario characterized by the lack of the dry port. This is not true for dry port located at a distance of between 17 and $21 \mathrm{~km}$ in which the strategy suggested by the model is most cost-effective but not ensuring the lower environmental impact. As concern the identification of the dry port located at distance

Table 1. Input and decision variables of DSS.

\begin{tabular}{|c|c|c|}
\hline $\mathrm{I} / \mathrm{O}$ variables & Class Parameters & Value \\
\hline I & $\begin{array}{l}\text { Containers } \\
\text { Data }\end{array}$ & $\begin{array}{c}N=800[\text { [units }] \\
d_{x}=6[\mathrm{~m}] ; d_{y}=2.4[\mathrm{~m}] ; d_{z}=2.9[\mathrm{~m}]\end{array}$ \\
\hline I & MHE features & $\begin{array}{c}v_{h}=6.39[\mathrm{~m} / \mathrm{s}] \approx 23[\mathrm{~km} / \mathrm{h}]^{\mathrm{a}} ; v_{v}=0.35[\mathrm{~m} / \mathrm{s}]^{\mathrm{a}} \\
v_{T R K}=50[\mathrm{~km} / \mathrm{h}] \\
\rho_{M H E}=15[1 / \mathrm{h}]^{\mathrm{b}} \rho_{T R K}=30[1 / 100 \mathrm{~km}]^{\mathrm{b}}\end{array}$ \\
\hline I & $\begin{array}{l}\text { Area and MHE } \\
\text { running costs }\end{array}$ & $\begin{array}{c}C_{M H E}=170[€ / \mathrm{h}] ; C_{T R K}=65\left[€ / \mathrm{h}^{*} \mathrm{u}\right] \\
C_{P O R T}=0.17\left[€ / \mathrm{h}^{*} \mathrm{~m}^{2}\right] ; C_{D P}=0.009\left[€ / \mathrm{h}^{*} \mathrm{~m}^{2}\right]^{\mathrm{c}}\end{array}$ \\
\hline I & Downtime & $T_{f}=0.033$ [h/unit] $\approx 120[\mathrm{~s} / \mathrm{unit}] ; T_{W}=24[\mathrm{~h}]$ \\
\hline 0 & Decision variables & $N_{1}=n_{x}{ }^{*} n_{v}{ }^{*} n_{z}$ [unit]; $N_{2}$ [unit]; $D[\mathrm{~km}]$ \\
\hline
\end{tabular}

${ }^{\mathrm{a}}$ Max travel and lifting speed of the RS adopted for containers handling, inside the seaport; ${ }^{\mathrm{b}}$ Average consumption for the RS and for truck; ${ }^{\mathrm{C}}$ Minimum cost estimated for a dry port area localized at distance of $25 \mathrm{~km}$ form seaport.
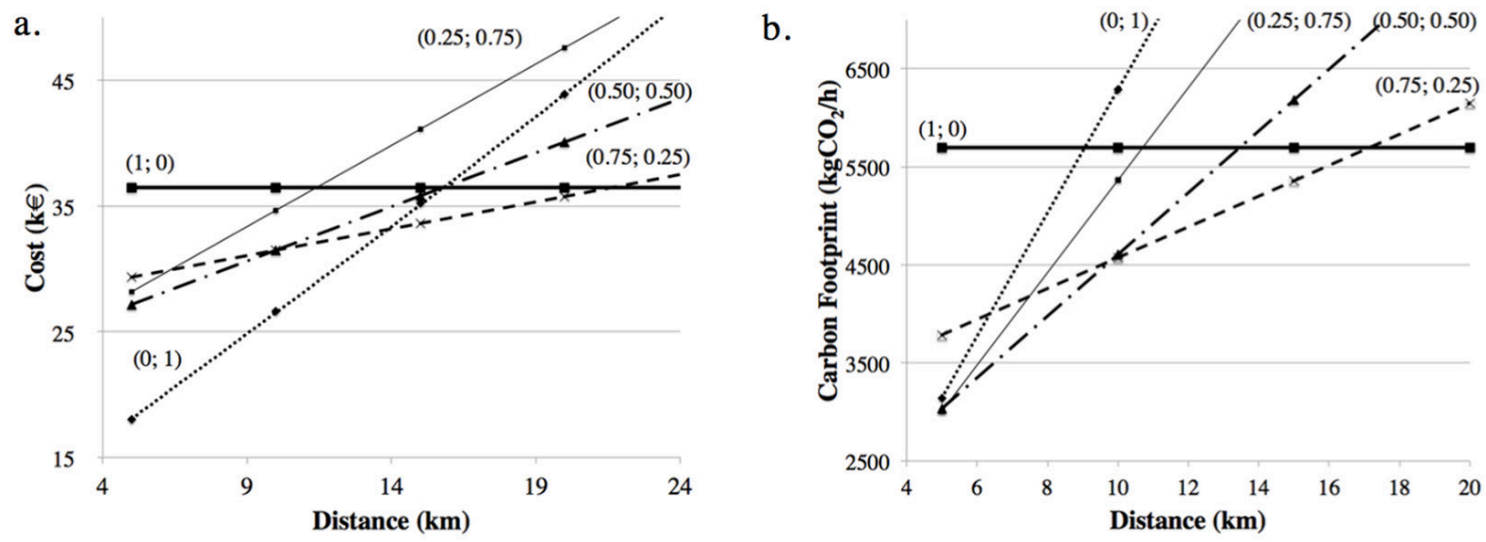

Figure 4. Evaluation of costs (a) and Carbon Footprint (b) adopting different strategies for the allocation of the containers in the seaport and in the dry port (in brackets $N_{l}$ and $N_{2}$ shown as percentages) by varying the distance of the dry port. 
greater or equal to $21 \mathrm{~km}$ the model not recommends the adoption of dry port both under the economical than then environmental perspective. In this case the cost and the carbon footprint due to container handling activities in a 'congested' seaport are the lowest.

There are further interesting consideration related to the number of containers stocked along the to z-axis $(n)$. Given the number of containers to be stored in the SA of the seaport $\left(N_{l}\right)$, the increase of the height of the stockpile $(n)$ leads to a reduction of the SA surface required. However, solutions with high $n_{z}$ values require more time for the containers handling activities. The adoption of the DSS allows identifying the most cost-effective strategy; in this case the model identifies in a block of containers characterized by 2 overlapping containers $(\mathrm{z}=2)$ the best strategy. It is very interesting noted that among the solutions identified by the model application, the configuration obtained with 5 overlapping containers $(z=5)$ reveals more cost-effective than the configuration for $\mathrm{z}=1$, that required the highest $\mathrm{SA}$ surface thus resulting as the most expensive. The cost due to the rental of the SA $\left(C_{P O R T}\right)$ doesn't affect the evaluation of the CF; therefore in this case the most eco-friendly solution will be obtained for stockpile characterized by the low height.

Finally, in Figure 5 the results of the comparison, under both a cost and an environmental perspective, between the strategies suggested by the DSS (for different $D$ values) and the strategy without the identification of a dry port are depicted. It is possible to claim that, in most cases, the DSS allows to identify strategies more cost-effective and characterized by lower $\mathrm{CO}_{2}$ emissions. It is very interesting note that in many cases the adoption of dry port allows to halve the costs and the carbon footprint due to containers handling.

a.

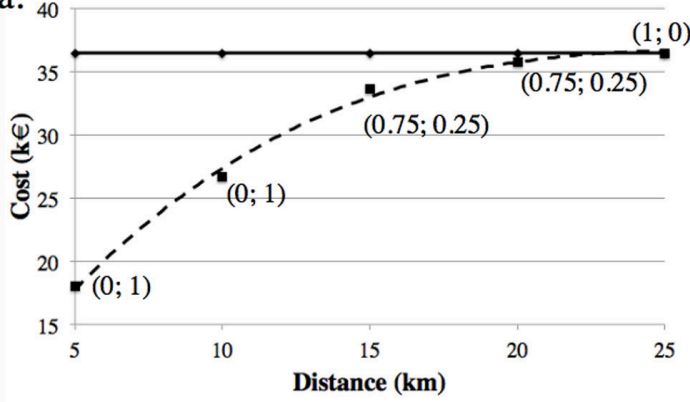

b.

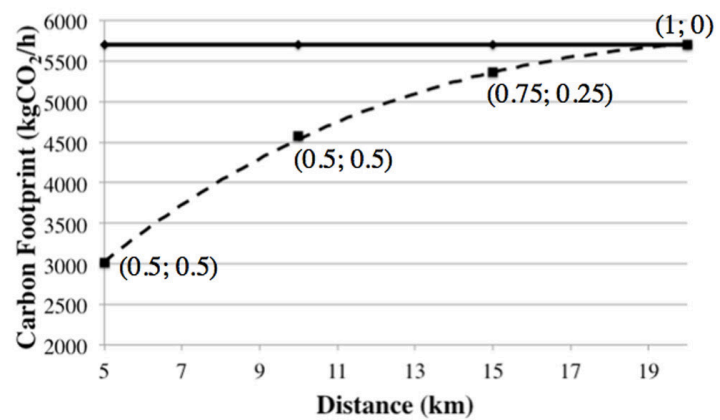

Figure 5. Comparison between strategies suggested (shown in bracket) by DSS and the strategy identified for $N_{2}=0$ (with no dry port) according cost (a) and carbon footprint evaluation (b).

\section{Conclusion}

The application of DSS to a full-scale numerical case show the model capabilities in identifying the optimal logistic strategies ensuring a low CF and in optimizing the cost due to containers handling in SA and transport activities. Results show how it is possible to identify different strategies (with or without a dry port identification) allowing to obtain an eco-friendly solution reducing, at same time, the costs for a given number of containers to be handled.

The main limit of the proposed model is related to the number of solutions suggested; in many cases there is not one unique solution, but there are, in the same conditions, two solutions: one that allows to optimize costs and another ensuring the minimization of the CF. Therefore the model has to be further developed in order to include more optimization criteria in its objective function. This will lead to apply it to more complex scenarios, thus ensuring greater flexibility and increasing the number of the industrial environments to be applied.

Future developments of the model presented can be oriented to evaluate further equipment related to the container handling management intra-/inter- terminal hub. In this case indeed, only one transport means is considered for the containers handling outside the seaport, this represents a constraint for a comprehensive assessment of the dry port implementation. Similar considerations concern the MHE adopted inside the seaport: in the DSS presented, only the performance of the reach stacker are considered for the handling of containers; by considering other MHEs will allow to evaluate the average picking and storage time due to adoption of one or more 'non-road' vehicles (e.g. rubber tyred crane, straddle carrier, etc.). Furthermore, in order to improve and extend the field of the application of the DSS, the evaluation of the KPls related to the dwell time and the 
transit time of the vessel on dock will be developed. The estimation of this kind of indicators would allow to evaluate the seaport efficiency and identify the best sustainable and cost-effective strategy allowing to fulfill the performance required by customers.

\section{References}

Agra, A., \& Oliveira, M. (2018). MIP approaches for the integrated berth allocation and quay crane assignment and scheduling problem. European Journal of Operational Research, 264(1), 138-148. http://dx.doi.org/10.1016/j.ejor.2017.05.040.

Ambrosino, D., \& Sciomachen, A. (2014). Location of mid-range dry ports in multimodal logistic networks. Procedia: Social and Behavioral Sciences, 108, 118-128. http://dx.doi.org/10.1016/j.sbspro.2013.12.825.

Ambrosino, D., \& Sciomachen, A. (2017). Investment evaluation in seaports for increasing the rail split modality in multimodal freight networks. In Proceedings of 2017 IEEE International Conference on Service Operations and Logistics, and Informatics (SOLI). Bari: IEEE. http://dx.doi.org/10.1109/SOLl.2017.8120991.

Amerini, G. (2010). Short sea shipping of goods 2008 (EU Publications, 26). Luxembourg: European Communities. Retrieved in 2018 , October 3, from https://publications.europa.eu/en/publication-detail/-/publication/dfc70923-65ad-41c2-adef-6d6befb871ee

Bazzazi, M., Safaei, N., \& Javadian, N. (2009). A genetic algorithm to solve the storage space allocation problem in a container terminal. Computers \& Industrial Engineering, 56(1), 44-52. http://dx.doi.org/10.1016/j.cie.2008.03.012.

Boenzi, F., Digiesi, S., Facchini, F., Mossa, G., \& Mummolo, G. (2015). Greening activities in warehouses: a model for identifying sustainable strategies in material handling. In Proceedings of 26th DAAAM International Symposium on Intelligent Manufacturing and Automation. Zadar: University of Zadar. Retrieved in 2018, October 3, from https://10.2507/26th.daaam.proceedings.138

Brinkmann, B. (2011). Operations systems of container terminals: a compendious overview. In J. Böse (Eds.), Handbook of terminal planning (Operations Research/Computer Science Interfaces Series, 49). New York: Springer. http://dx.doi.org/10.1007/978-1-4419-8408-1_2.

Carlo, H. J., Vis, I. F. A., \& Roodbergen, K. J. (2014a). Transport operations in container terminals: Literature overview, trends, research directions and classification scheme. European Journal of Operational Research, 236(1), 1-13. http://dx.doi.org/10.1016/j.ejor.2013.11.023.

Carlo, H. J., Vis, l. F. A., \& Roodbergen, K. J. (2014b). Storage yard operations in container terminals: literature overview, trends, and research directions. European Journal of Operational Research, 235(2), 412-430. http://dx.doi.org/10.1016/j.ejor.2013.10.054.

Carlo, H. J., Vis, l. F. A., \& Roodbergen, K. J. (2015). Seaside operations in container terminals: literature overview, trends, and research directions. Flexible Services and Manufacturing Journal, 27(2-3), 224-262. http://dx.doi.org/10.1007/s10696-013-9178-3.

Cheung, R. K., Li, C.-L., \& Lin, W. (2002). Interblock crane deployment in container terminals. Transportation Science, 36(1), 79-93. http://dx.doi.org/10.1287/trsc.36.1.79.568.

Crainic, T. G., Dell'Olmo, P., Ricciardi, N., \& Sgalambro, A. (2015). Modeling dry-port-based freight distribution planning. Transportation Research Part C: Emerging Technologies, 55, 518-534. http://dx.doi.org/10.1016/j.trc.2015.03.026.

Dekker, R., Voogd, P., \& van Asperen, E. (2006). Advanced methods for container stacking. OR-Spektrum, 28(4), 563-586. http://dx.doi. org/10.1007/s00291-006-0038-3.

Digiesi, S., Mascolo, G., Mossa, G., \& Mummolo, G. (2016). New models for sustainable logistics: internalization of external costs in inventory management (SpringerBriefs in Operations Management). Cham: Springer. http://dx.doi.org/10.1007/978-3-319-19710-4.

Digiesi, S., Mossa, G., \& Mummolo, G. (2013). Supply lead time uncertainty in a sustainable order quantity inventory model. Management and Production Engineering Review, 4(4), 15-27. http://dx.doi.org/10.2478/mper-2013-0034.

Digiesi, S., Mossa, G., \& Rubino, S. (2012). Sustainable order quantity of repairable spare parts. IFAC Proceedings Volumes, 45(31), 181-186. http://dx.doi.org/10.3182/20121122-2-ES-4026.00043.

Digiesi, S., Mossa, G., \& Rubino, S. (2015). A sustainable EOQ model for repairable spare parts under uncertain demand. IMA Journal of Management Mathematics, 26(2), 185-203. http://dx.doi.org/10.1093/imaman/dpu004.

Drewry Maritime Advisors. (2015). Trends in ports and shipping market: prospects for the coming years. Drewry. Retrieved in 2018, October 3, from http://www.bpoports.com/BPC/Riga/presentations/Sharma.pdf

Facchini, F., Mummolo, G., Mossa, G., Digiesi, S., Boenzi, F., \& Verriello, R. (2016). Minimizing the carbon footprint of material handling equipment: comparison of electric and LPG forklifts. Journal of Industrial Engineering and Management, 9(5), 1035-1046. http:// dx.doi.org/10.3926/jiem.2082.

Froyland, G., Koch, T., Megow, N., Duane, E., \& Wren, H. (2007). Optimizing the land- side operation of a container terminal. ORSpektrum, 30(1), 53-75. http://dx.doi.org/10.1007/s00291-007-0082-7.

Harris, l., Wang, Y., \& Wang, H. (2015). ICT in multimodal transport and technological trends: unleashing potential for the future. International Journal of Production Economics, 159, 88-103. http://dx.doi.org/10.1016/j.jpe.2014.09.005.

Kadir, E. A. (2017). Development of Information and Communication Technology (ICT) in container terminal for speed up clearance process. Journal of Communication, 12(4), 207-213.

Kiani, M., Sayareh, J., \& Nooramin, S. (2010). A simulation framework for optimizing truck congestions in marine terminals. Journal for Maritime Research, 7(1), 55-70. Retrieved in 2018, October 3, from https://www.jmr.unican.es/index.php/jmr/article/view/128

Kim, K. H., Park, Y. M., \& Ryu, K. R. (2000). Deriving decision rules to locate export containers in container yards. European Journal of Operational Research, 124(1), 89-101. http://dx.doi.org/10.1016/S0377-2217(99)00116-2.

$\mathrm{Ku}$, D., \& Arthanari, T. S. (2016). Container relocation problem with time windows for container departure. European Journal of Operational Research, 252(3), 1031-1039. http://dx.doi.org/10.1016/j.ejor.2016.01.055.

Le, X. T., \& Knust, S. (2017). MIP-based approaches for robust storage loading problems with stacking constraints. Computers \& Operations Research, 78, 138-153. http://dx.doi.org/10.1016/j.cor.2016.08.016.

Legato, P., \& Mazza, R. M. (2017). A simulation model for designing straddle carrier-based container terminals. In Proceedings of 2017 Winter Simulation Conference (WSC) (pp. 3138-3149). Las Vegas: IEEE. http://dx.doi.org/10.1109/WSC.2017.8248033. 
Liao, C. H., Tseng, P. H., \& Lu, C. S. (2009). Comparing carbon dioxide emissions of trucking and intermodal container transport in Taiwan. Transportation Research Part D: Transport and Environment, 14(7), 493-496. http://dx.doi.org/10.1016/j.trd.2009.05.002.

Lin, D.-Y., \& Chiang, C.-W. (2017). The storage space allocation problem at a container terminal. Maritime Policy \& Management, 44(6), 685-704. http://dx.doi.org/10.1080/03088839.2017.1335897.

Nguyen, L. C., \& Notteboom, T. (2016). A multi-criteria approach to dry port location in developing economies with application to Vietnam. The Asian Journal of Shipping and Logistics, 32(1), 23-32. http://dx.doi.org/10.1016/j.ajsl.2016.03.003.

Padilha, F., \& Ng, A. K. Y. (2012). The spatial evolution of dry ports in developing economies: the Brazilian experience. Maritime Economics \& Logistics, 14(1), 99-121. http://dx.doi.org/10.1057/mel.2011.18.

Phan, M.-H., \& Kim, K. H. (2015). Negotiating truck arrival times among trucking companies and a container terminal. Transportation Research Part E: Logistics and Transportation Review, 75, 132-144. http://dx.doi.org/10.1016/j.tre.2015.01.004.

Roso, V., Woxenius, J., \& Lumsden, K. (2009). The dry port concept: connecting container seaports with the hinterland. Journal of Transport Geography, 17(5), 338-345. http://dx.doi.org/10.1016/j.jtrangeo.2008.10.008.

Venturini, G., lris, C., Kontovas, C. A., \& Larsen, A. (2017). The multi-port berth allocation problem with speed optimization and emission considerations. Transportation Research Part D: Transport and Environment, 54, 142-159. http://dx.doi.org/10.1016/j.trd.2017.05.002.

Zanni, A. M., \& Bristow, A. L. (2010). Emissions of C02 from road freight transport in London: trends and policies for long run reductions. Energy Policy, 38(4), 1774-1786. http://dx.doi.org/10.1016/j.enpol.2009.11.053.

Zhang, C., Liu, J., Wan, Y. W., Murty, K. G., \& Linn, R. J. (2003). Storage space allocation in container terminals. Transportation Research Part B: Methodological, 3710), 883-903. http://dx.doi.org/10.1016/S0191-2615(02)00089-9. 